\title{
Molecular Characterization of Peruvian Fowl Adenovirus (FAdV) Isolates
}

\author{
Jorge Rodríguez*, Ysabel Koga, Arnaldo Alvarado, Robert Tinoco \\ Bioservice SRL, Lima, Peru \\ Email: ${ }^{*}$ jrodriguez@bioservice.com.pe, jorge.rodriguez.b@upch.pe
}

Received 27 June 2014; revised 19 July 2014; accepted 1 August 2014

Copyright (C) 2014 by authors and Scientific Research Publishing Inc.

This work is licensed under the Creative Commons Attribution International License (CC BY). http://creativecommons.org/licenses/by/4.0/

(c) (i) Open Access

\begin{abstract}
Forty seven clinical samples of Fowl adenovirus (FAdV) associated with Inclusion Body Hepatitis (IBH) from Peruvian broilers received between July 2006 and April 2013 were genotyped using sequencing of L1 Loop of Hexon gene. All 47 clinical samples presented macroscopic and histopathology lesions consistent with IBH, and amplified a specific fragment of Hexon gene by Polymerase Chain Reaction (PCR). A unique nucleotide sequence of 789 base pairs of Hexon gene (position 273 to 1061) was obtained in all 47 clinical samples analyzed. This sequence showed a high level of conservation in amino acid and nucleotide sequence $(>99 \%)$ with a Fowl Adenovirus $\mathrm{C}$ serotype 4 previously identified. Sequence and phylogenetic analysis indicate no genotypic variation in Peruvian isolates. The presence of a unique genotype very closely related with genotype C1 previously reported in Peru and Ecuador ( $>99 \%)$, suggests the presence of FAdV C serotype 4 genotype $\mathrm{C} 1$ in clinical cases of IBH from Peruvian broilers.
\end{abstract}

\section{Keywords}

Fowl Adenovirus C, Molecular Characterization, Inclusion Body Hepatitis, Peru

\section{Introduction}

Fowl Adenovirus (FAdV) includes 12 serotypes [1], with a high diversity of strains for each serotype and a wide range of clinical and pathological presentations (pneumonias, tracheitis, gizzard erosions, proventriculitis, pancreatitis, inclusion body hepatitis and hydropericardium) [2]. The most important sanitary problem in North America and South America is inclusion body hepatitis/hydropericardium syndrome due to high levels of morbidity and mortality in broilers resulting in significant economic losses [3]-[7]. This great diversity exhibited by FAdV required the use of additional techniques to make a correct identification of levels of species and serotypes and characterization of genetic diversity. An alternative to microbiologic and serologic techniques are

${ }^{*}$ Corresponding author.

How to cite this paper: Rodríguez, J., Koga, Y., Alvarado, A. and Tinoco, R. (2014) Molecular Characterization of Peruvian Fowl Adenovirus (FAdV) Isolates. Advances in Microbiology, 4, 595-603. http://dx.doi.org/10.4236/aim.2014.410065 
molecular techniques based on DNA analysis. Several studies have reported the feasibility of molecular genetic tools for genetic differentiation and molecular typing of FAdV. The use of PCR for Hexon gene, RFLP analysis and direct sequencing of Hexon and Penton genes [8]-[10] have permitted a correct identification and characterization of clinical isolates. The lack of information available for molecular characterization of isolates from Peru do not allow the identification of the type of serotypes currently present in poultry production systems. This is a key requirement for establishing actions to control and prevent IBH. The objective of this study was to determine FAdV genotypes/serotypes isolated from IBH clinical cases in broilers from Peru.

\section{Materials and Methods}

\subsection{Sources of Samples}

A total of 47 suspected clinical cases of Inclusion body hepatitis (IBH) from broilers received in the Microbiology Laboratory-Bioservice SRL between July 2006 and April 2013 were included in this study (Table 1). Agar gel immune-diffusion (AGID) tests for serotypes 4, 8 and 9, liver histopathology analysis and Hexon gene PCR were performed to confirm the presence of fowl adenovirus (FAdV) in all suspected clinical cases.

\subsection{Viral DNA Extraction and PCR Amplification of Hexon Gene}

Viral DNA was extracted from liver lysate using DNeasy Tissue kit (Qiagen) according to manufacturer. PCR for L1 loop of the Hexon gene was carried out using primers HA and HB as described previously [9]. In brief, the PCR reaction was performed using a final volume of $20 \mathrm{uL}$ containing $10 \mathrm{ng}$ genomic DNA, 1X PCR buffer (20 mM Tris-HCl, $20 \mathrm{mM} \mathrm{KCl,} 5 \mathrm{mM}(\mathrm{NH} 4)_{2} \mathrm{SO}_{4}$ ), $2 \mathrm{mM} \mathrm{MgCl}$, 5 pmol of each primer, $0.2 \mathrm{mM}$ of dNTPs, 0.5 U Maxima HotStart-Taq DNA polymerase (Fermentas). Thermal cycles were the following: initial denaturation of $94^{\circ} \mathrm{C}$ for 3 minutes, 30 cycles of $94^{\circ} \mathrm{C}$ for 30 seconds, $53^{\circ} \mathrm{C}$ for 60 seconds, $72^{\circ} \mathrm{C}$ for 30 seconds and a final extension of $72^{\circ} \mathrm{C}$ for 5 minutes. The PCR amplification was carried out using a Veriti Thermal cycler (Applied Biosystems). The PCR products were separated in 1\% agarose gel TBE 1X electrophoresis and visualized by fluorescence using an ethidium bromide solution $(0.1 \mathrm{ug} / \mathrm{mL})$ and UV light.

\subsection{Sequencing and Phylogenetics Analysis of L1 Loop of Hexon Gene}

The PCR products were purified using the Wizard ${ }^{\circledR}$ SV Gel and PCR Clean-Up kit, cloned with pGEM-T Easy (Promega) and submitted for sequencing to Macrogen Inc, Korea. The sequencing reaction was performed in both directions using Big Dye sequencing kit (Applied Biosystems) and the primers HA and HB. Partial nucleotide sequence of the L1 Loop of hexon gene from FAdV's was submitted to Gene Bank with the following accession number: KF601685.

Forward and reverse sequences were aligned together using Clustal program [11] to create consensus sequences. The consensus nucleotide sequences were aligned by the Clustal W method using MEGA 5.0 software [12]. Pairwise amino acid and nucleotide identity and pairwise evolutionary distances were computed using

Table 1. Collection year and city of origin of 47 clinical cases of Inclusion body hepatitis (IBH) from broilers from Peru.

\begin{tabular}{ccc}
\hline Year of isolation & $\begin{array}{c}\text { Place of isolation } \\
\text { (City, Province) }\end{array}$ & Number of isolates \\
2006, 2007, 2011, 2012, 2013 & Lima, Lima & 20 \\
$2011,2012,2013$ & Chilca, Lima & 12 \\
$2011,2012,2013$ & Iquitos, Loreto & 2 \\
2011 & Arequipa, Arequipa \\
2011 & Tacna, Tacna \\
2011 & Chanchamayo, Junin \\
2011 & Nazca, Ica \\
$2006,2007,2012,2013$ & Trujillo, La Libertad \\
\hline
\end{tabular}


Mega v5.0. A phylogenetic analysis for the distance method was performed using partial sequences of L1 loop of Hexon gene and Hexon protein previously published in Gene Bank and FAdV Peruvian sequence (Table 2)

Table 2. ID sequence, accession number, country of origin, species, serotype and genetic cluster of 37 FAdV using phylogenetic analysis.

\begin{tabular}{|c|c|c|c|c|c|}
\hline ID Sequence & Accession number ${ }^{1}$ & Country $^{2}$ & Species $^{3}$ & Serotype $^{4}$ & Genetic Cluster \\
\hline FAdV_1_(CELO) & AAL13217 & $\mathrm{NR}^{6}$ & A & EU/US 1 & A \\
\hline FAdV_2_(SR48) & AAN77072 & $\mathrm{NR}^{6}$ & $\mathrm{D}$ & EU 2 & $\mathrm{D} 2$ \\
\hline FAdV_3_(75) & AAN77075 & $\mathrm{NR}^{6}$ & $\mathrm{D}$ & EU 3 & D3 \\
\hline FAdV_4_(KR5) & AAN77077 & $\mathrm{NR}^{6}$ & $\mathrm{C}$ & EU 4 & $\mathrm{C}$ \\
\hline FAdV_5_(VR-830) & AAL13222 & $\mathrm{NR}^{6}$ & $\mathrm{E}$ & US 5 & D1 \\
\hline FAdV_5_(TR22) & AAN77079 & $\mathrm{NR}^{6}$ & B & EU 5 & $\mathrm{E}$ \\
\hline FAdV_5_(340) & AAN77078 & $\mathrm{NR}^{6}$ & B & EU 5 & B \\
\hline FAdV_6_(VR-831) & AAL13224 & $\mathrm{NR}^{6}$ & $\mathrm{D}$ & US 6 & D3 \\
\hline FAdV_6_(CR119) & AAN77080 & $\mathrm{NR}^{6}$ & $\mathrm{E}$ & EU 6 & D1 \\
\hline FAdV_7_(YR36) & AAN77081 & $\mathrm{NR}^{6}$ & $\mathrm{E}$ & EU 7 & D1 \\
\hline FAdV_7_(VR-832) & AAL13225 & $\mathrm{NR}^{6}$ & $\mathrm{E}$ & EU 7 & $\mathrm{D} 1$ \\
\hline FAdV_8_(TR59) & AAN77082 & $\mathrm{NR}^{6}$ & $\mathrm{E}$ & EU 8 & $\mathrm{D} 1$ \\
\hline FAdV_8_(VR-833) & AAL13221 & $\mathrm{NR}^{6}$ & $\mathrm{D}$ & US 8 & D3 \\
\hline FAdV_9_(VR-834) & AAL13226 & $\mathrm{NR}^{6}$ & $\mathrm{C}$ & US 9 & $\mathrm{C}$ \\
\hline FAdV_9_(764) & AAN77084 & $\mathrm{NR}^{6}$ & $\mathrm{E}$ & EU 9 & D1 \\
\hline FAdV_10_(VR-835) & AAL13227 & $\mathrm{NR}^{6}$ & $\mathrm{E}$ & US 10 & D1 \\
\hline FAdV_11_(X11) & AAL13223 & $\mathrm{NR}^{6}$ & $\mathrm{E}$ & US 11 & D1 \\
\hline FAdV_11_(C2B) & AAN77085 & $\mathrm{NR}^{6}$ & $\mathrm{C}$ & EU 11 & $\mathrm{D} 2$ \\
\hline FAdV_12_(380) & AAL13228 & $\mathrm{NR}^{6}$ & $\mathrm{D}$ & US 12 & $\mathrm{D} 2$ \\
\hline (922-1)_Germany & FN869978.1 & Germany & $\mathrm{C}$ & EU/US 4 & $\mathrm{C}$ \\
\hline (09-2602)_Austria & FN869977.1 & Austria & $\mathrm{C}$ & EU/US 4 & $\mathrm{C}$ \\
\hline (K31)_Pakistan & FN869976.1 & Pakistan & $\mathrm{C}$ & EU/US 4 & $\mathrm{C}$ \\
\hline (09-584)_Austria & FN869975.1 & Austria & $\mathrm{C}$ & EU/US 4 & $\mathrm{C}$ \\
\hline (53)_Peru & FN869973.1 & Peru & $\mathrm{C}$ & EU/US 4 & $\mathrm{C}$ \\
\hline (K1013)_Ecuador & FN869972.1 & Ecuador & $\mathrm{C}$ & EU/US 4 & $\mathrm{C}$ \\
\hline (Da60)_Germany & FN869971.1 & Germany & $\mathrm{C}$ & EU/US 4 & $\mathrm{C}$ \\
\hline (K99-97)_Kuwait & FN869970.1 & Kuwait & $\mathrm{C}$ & EU/US 4 & $\mathrm{C}$ \\
\hline (AG234)_Mexico & FN869969.1 & Mexico & $\mathrm{C}$ & EU/US 4 & $\mathrm{C}$ \\
\hline South_Korea & HQ697593.1 & South Korea & $\mathrm{C}$ & EU/US 4 & $\mathrm{C}$ \\
\hline (04-50388)_Canada & EF685395.1 & Canada & $\mathrm{C}$ & EU/US 4 & $\mathrm{C}$ \\
\hline (488)_Russia & AY581295.1 & Russia & $\mathrm{C}$ & EU/US 4 & $\mathrm{C}$ \\
\hline (4158)_Italy & HM592284.1 & Italy & $\mathrm{C}$ & EU/US 4 & $\mathrm{C}$ \\
\hline (5997)_Italy & HM592281.1 & Italy & $\mathrm{C}$ & EU/US 4 & $\mathrm{C}$ \\
\hline (6169)_Italy & HM592277.1 & Italy & $\mathrm{C}$ & EU/US 4 & $\mathrm{C}$ \\
\hline (5670)_Italy & HM592274.1 & Italy & $\mathrm{C}$ & EU/US 4 & $\mathrm{C}$ \\
\hline (488)_Indian & AY581295.1 & India & $\mathrm{C}$ & EU/US 4 & $\mathrm{C}$ \\
\hline (HARYANA-07)_Indian & EU847626.1 & India & $\mathrm{C}$ & EU/US 4 & $\mathrm{C}$ \\
\hline
\end{tabular}

${ }^{1}$ Accesion number for Hexon protein or sequence in database Genbank or EMBL. ${ }^{2}$ Country of origin of strain. ${ }^{3}$ Fowl Adenovirus species according with [10]. ${ }^{4}$ Fowl Adenovirus serotype according with [1]. ${ }^{5}$ Fowl Adenovirus phylogenetic cluster according with [10]. ${ }^{6}$ No reported in [10]. 
using Kimura-2-parameter method [13] and Dayhoff matrix based method [14]. A dendogram was constructed with the Neighbor-joining method [15] using 1000 bootstrap [16] replicate values with Mega v5.0.

\section{Results}

\subsection{Clinical Cases of Inclusion Body Hepatitis}

All clinical cases presented liver histopathology consistent with IBH lesions hepatocyte cytoplasmic vacuolation, multifocal to coalescing areas of hepatocytes necrosis, irregular shape hepatocyte nuclei, presence of basophilic intranuclear inclusion bodies without presence of HPS. The presence of FAdV was confirmed by PCR amplification of Hexon gene fragment in 47 suspected clinical cases of IBH.

\subsection{Sequencing and Phylogenetic Analysis of L1 Loop of Hexon Gene}

All 47 Peruvian FAdV isolates did not show genotype variation, a unique nucleotide sequence of 789 bp corresponding to position 273 and 1061 of Hexon gene amplified showed high nucleotide identity level (99.5\% identity, E value $=0$ ) and high conservation level in the amino acidic sequence $(99.5 \%)$ in relation with a FAdV C serotype 4 previously identified [10]. The pairwise matrix of evolutionary divergence (nucleotide and amino acid) showed less divergence between Peruvian FAdV with FAdV C serotype $4(0.005,0.005)$ and FAdV C serotype US $9(0.029,0.070)$ in contrast to FAdV D serotype $8(0.365,0.709)$ and serotype $12(0.378$ and 0.663$)$ (Table 3). Phylogenetic analysis from a segment of 770 nucleotide (260 amino acids) suggests the presence of FAdV group C serotype 4 present in all clinical cases from IBH of Peruvian broilers (Figure 1(a) and

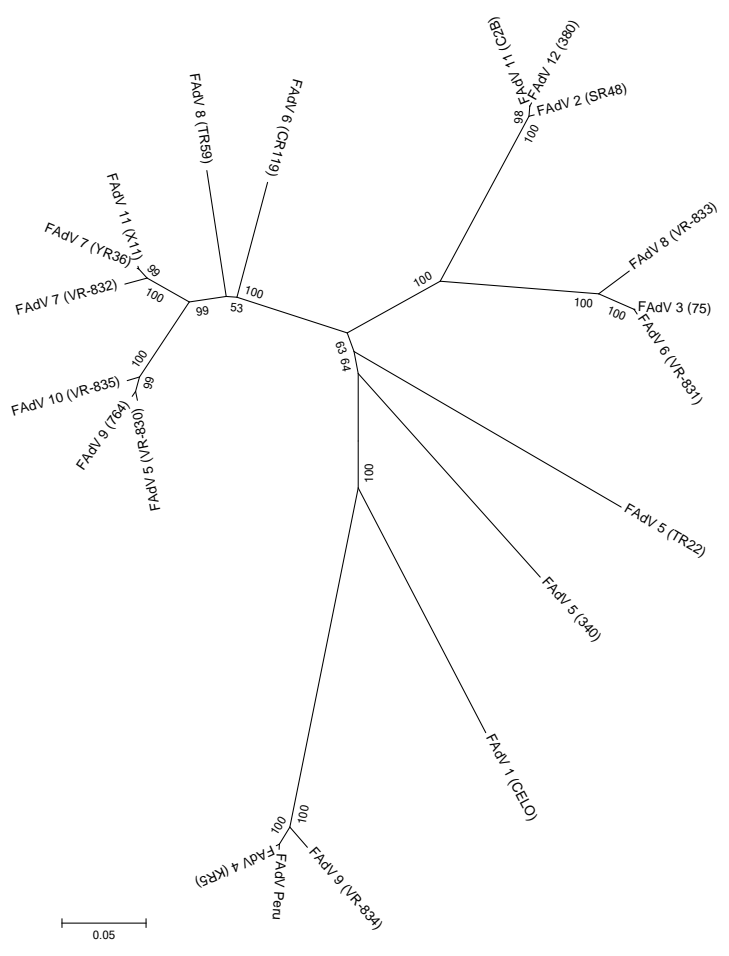

(a)

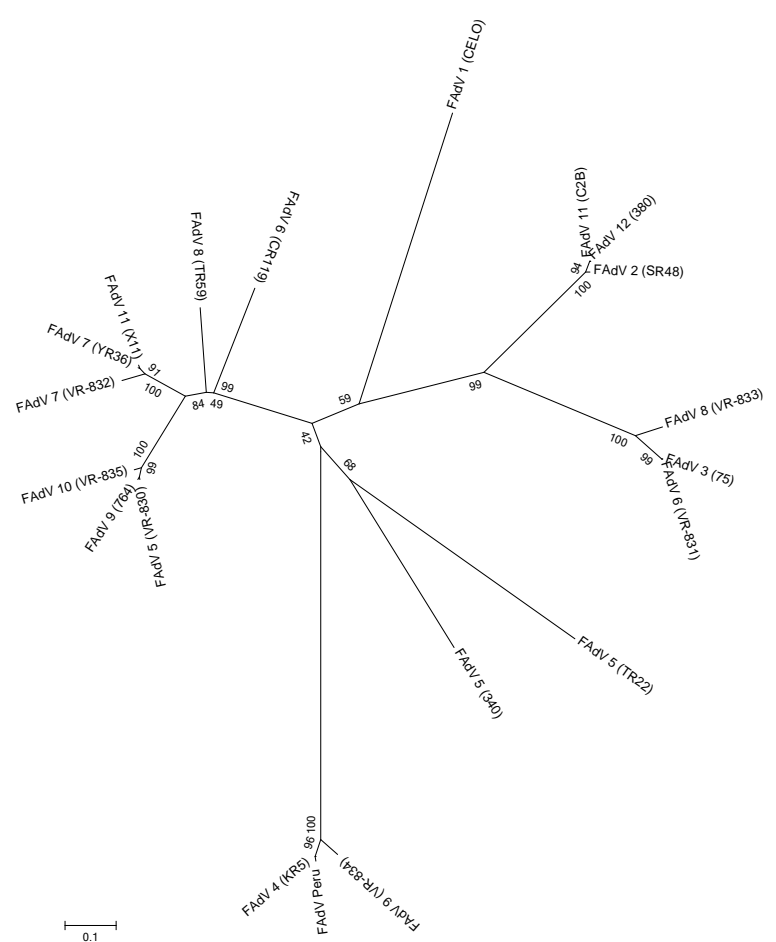

(b)

Figure 1. (a) Phylogenetic tree of L1 loop of the hexon nucleotide sequence from 12 species of FAdV's. The evolutionary relationships of taxa were inferred using Neighbor-Joining method [17]. The evolutionary distances were computed using the Kimura 2-parameter method [13]. The analysis involved 20 nucleotide sequences and 770 nucleotide positions in the final dataset, the strain names are according to Table 2. Bootstrap [16] test (1000 replicates) is expressed in \% values. The scale bar indicates the evolutionary distance between sequences; (b) Phylogenetic tree of L1 loop of the hexon protein sequence from 12 species of FAdV's. The evolutionary relationships of taxa were inferred using Neighbor-Joining method [17]. The evolutionary distances were computed using the Dayhoff matrix method [14]. The analysis involved 20 amino acid sequences and 199 amino acid positions in the final dataset, the strain names are according to Table 2. Bootstrap [16] test (1000 replicates) is expressed in \% values. The scale bar indicates the evolutionary distance between sequences. 
Table 3. Pairwise estimates of evolutionary divergence ${ }^{1}$ of nucleotide sequence (below diagonal) and amino acid sequence (above diagonal) between 12 species of $\mathrm{FAdV}^{2}$.

\begin{tabular}{|c|c|c|c|c|c|c|c|c|c|c|c|c|c|c|c|c|c|c|c|c|}
\hline & $\sum_{\text {死 }}$ & $\sum_{\text {¿ }}^{5}$ & $\sum_{i=1}^{N}$ & $\sum_{\substack{1 \\
1}}^{\infty}$ & $\sum_{\substack{\mathbb{1}\\
}}^{ \pm}$ & 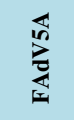 & 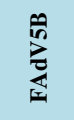 & 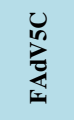 & 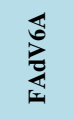 & 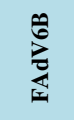 & $\sum_{\substack{\mathbb{1} \\
\mathbb{1}}}^{\mathbb{K}}$ & 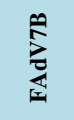 & 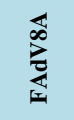 & $\sum_{\substack{\infty\\
}}^{\infty}$ & 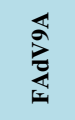 & 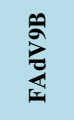 & 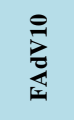 & 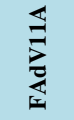 & 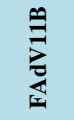 & 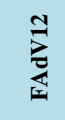 \\
\hline FAdVPeru & & 0.628 & 0.663 & 0.704 & 0.005 & 0.603 & 0.663 & 0.573 & 0.704 & 0.568 & 0.578 & 0.573 & 0.548 & 0.709 & 0.070 & 0.603 & 0.598 & 0.583 & 0.663 & 0.663 \\
\hline FAdV1 & 0.300 & & 0.573 & 0.608 & 0.628 & 0.583 & 0.648 & 0.598 & 0.608 & 0.603 & 0.553 & 0.563 & 0.578 & 0.603 & 0.618 & 0.583 & 0.598 & 0.553 & 0.563 & 0.563 \\
\hline FAdV2 & 0.374 & 0.335 & & 0.432 & 0.663 & 0.558 & 0.663 & 0.563 & 0.432 & 0.508 & 0.543 & 0.528 & 0.528 & 0.427 & 0.658 & 0.558 & 0.553 & 0.538 & 0.030 & 0.030 \\
\hline FAdV3 & 0.366 & 0.323 & 0.203 & & 0.704 & 0.568 & 0.588 & 0.588 & 0.000 & 0.588 & 0.563 & 0.558 & 0.578 & 0.101 & 0.724 & 0.568 & 0.573 & 0.563 & 0.417 & 0.417 \\
\hline FAdV4 & 0.005 & 0.299 & 0.374 & 0.365 & & 0.603 & 0.663 & 0.573 & 0.704 & 0.568 & 0.578 & 0.573 & 0.548 & 0.709 & 0.070 & 0.603 & 0.598 & 0.583 & 0.663 & 0.663 \\
\hline FAdV5A & 0.353 & 0.321 & 0.278 & 0.273 & 0.352 & & 0.573 & 0.543 & 0.568 & 0.317 & 0.216 & 0.246 & 0.271 & 0.563 & 0.613 & 0.010 & 0.035 & 0.221 & 0.563 & 0.563 \\
\hline FAdV5B & 0.361 & 0.340 & 0.303 & 0.264 & 0.360 & 0.278 & & 0.533 & 0.588 & 0.573 & 0.558 & 0.568 & 0.543 & 0.598 & 0.653 & 0.573 & 0.568 & 0.558 & 0.653 & 0.653 \\
\hline FAdV5C & 0.332 & 0.312 & 0.295 & 0.305 & 0.331 & 0.284 & 0.271 & & 0.588 & 0.503 & 0.523 & 0.518 & 0.528 & 0.583 & 0.588 & 0.543 & 0.538 & 0.518 & 0.563 & 0.563 \\
\hline FAdV6A & 0.369 & 0.326 & 0.205 & 0.003 & 0.368 & 0.275 & 0.266 & 0.308 & & 0.588 & 0.563 & 0.558 & 0.578 & 0.101 & 0.724 & 0.568 & 0.573 & 0.563 & 0.417 & 0.417 \\
\hline FAdV6B & 0.339 & 0.313 & 0.240 & 0.258 & 0.339 & 0.151 & 0.279 & 0.262 & 0.261 & & 0.286 & 0.281 & 0.302 & 0.573 & 0.563 & 0.322 & 0.312 & 0.286 & 0.533 & 0.533 \\
\hline FAdV7A & 0.336 & 0.301 & 0.262 & 0.268 & 0.336 & 0.096 & 0.278 & 0.265 & 0.270 & 0.117 & & 0.055 & 0.231 & 0.568 & 0.578 & 0.221 & 0.211 & 0.010 & 0.553 & 0.553 \\
\hline FAdV7B & 0.331 & 0.305 & 0.257 & 0.264 & 0.332 & 0.105 & 0.277 & 0.264 & 0.266 & 0.116 & 0.021 & & 0.266 & 0.568 & 0.573 & 0.241 & 0.241 & 0.065 & 0.543 & 0.543 \\
\hline FAdV8A & 0.339 & 0.310 & 0.249 & 0.274 & 0.339 & 0.145 & 0.270 & 0.268 & 0.277 & 0.140 & 0.122 & 0.135 & & 0.573 & 0.543 & 0.271 & 0.256 & 0.236 & 0.533 & 0.533 \\
\hline FAdV8B & 0.365 & 0.323 & 0.200 & 0.044 & 0.364 & 0.271 & 0.275 & 0.308 & 0.047 & 0.260 & 0.265 & 0.264 & 0.279 & & 0.714 & 0.563 & 0.573 & 0.568 & 0.412 & 0.412 \\
\hline FAdV9A & 0.029 & 0.301 & 0.371 & 0.368 & 0.031 & 0.353 & 0.355 & 0.334 & 0.370 & 0.340 & 0.339 & 0.336 & 0.338 & 0.364 & & 0.613 & 0.613 & 0.583 & 0.668 & 0.668 \\
\hline FAdV9B & 0.355 & 0.322 & 0.277 & 0.271 & 0.353 & 0.009 & 0.278 & 0.283 & 0.274 & 0.151 & 0.094 & 0.100 & 0.145 & 0.271 & 0.355 & & 0.035 & 0.226 & 0.563 & 0.563 \\
\hline FAdV11A & 0.338 & 0.300 & 0.260 & 0.266 & 0.338 & 0.097 & 0.277 & 0.262 & 0.269 & 0.117 & 0.003 & 0.023 & 0.123 & 0.264 & 0.340 & 0.095 & 0.091 & & 0.548 & 0.548 \\
\hline FAdV11B & 0.378 & 0.332 & 0.010 & 0.199 & 0.378 & 0.281 & 0.296 & 0.295 & 0.201 & 0.248 & 0.269 & 0.262 & 0.252 & 0.196 & 0.378 & 0.279 & 0.277 & 0.266 & & 0.000 \\
\hline FAdV12 & 0.378 & 0.335 & 0.010 & 0.201 & 0.378 & 0.282 & 0.299 & 0.296 & 0.204 & 0.248 & 0.270 & 0.262 & 0.253 & 0.199 & 0.378 & 0.281 & 0.278 & 0.268 & 0.003 & \\
\hline
\end{tabular}

${ }^{1}$ Analyses were conducted using p-distance [18]. This distance is the proportion (p) of amino acid (nucleotide) sites at which the two sequences to be compared are different. ${ }^{2}$ The FAdV strain accession number: FAdV1 (AAL13217), FAdV2 (AAN77072), FAdV3 (AAN77075), FAdV4 (AAN77077), FAdV5A (AAL13222), FAdV5B (AAN77079), FAdV5C (AAN77078), FAdV6A (AAL13224), FAdV6B (AAN77080), FAdV7A (AAN77081), FAdV7B (AAL13225), FAdV8A (AAN77082), FAdV8B (AAL13221), FAdV9A (AAL13226), FAdV9B (AAN77084), FAdV10 (AAL13227), FAdV11A (AAL13223), FAdV11B (AAN77085), FAdV12 (AAL13228) and FAdVPeru (this study).

Figure 1(b)). The FAdV genotype identified is closely related with the genotype C1 [19] previously reported in Peru (evolutionary divergence $=0,100 \%$ nucleotide identity) and Ecuador (evolutionary divergence $=0.002$, 99.9\% nucleotide identity), however the two isolates showed $100 \%$ amino acid identity with FAdV isolated in this study (Table 4); this relationship is corroborated by phylogenetic clustering analysis (Figure 2(a) and Figure 2(b)).

\section{Discussion}

The nucleic acid technology has demonstrated the utility to detect differences in structural proteins related with immune response as Hexon protein. The sequencing of Hexon gene permits a correct identification of species level and serotype in FAdV, with similar results as reported for RFLP genome analysis [2]. Inside Hexon gene, 7 hypervariable regions were identified exclusively located in Loop 1 (L1) and Loop 2 (L2) regions [20]. The loop 1 in Hexon gene of FAdV reported higher variability [8], and has demonstrated additional applications than include genetic variability analysis of FAdV isolates [6] [10] [21]. 


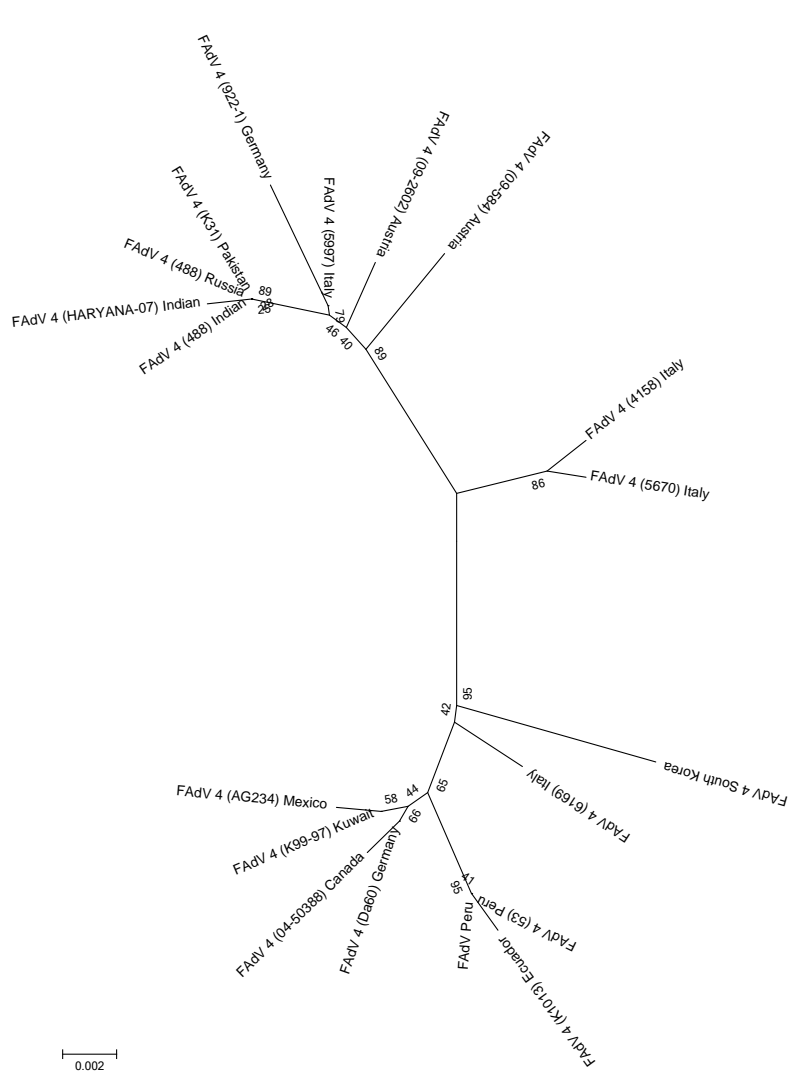

(a)

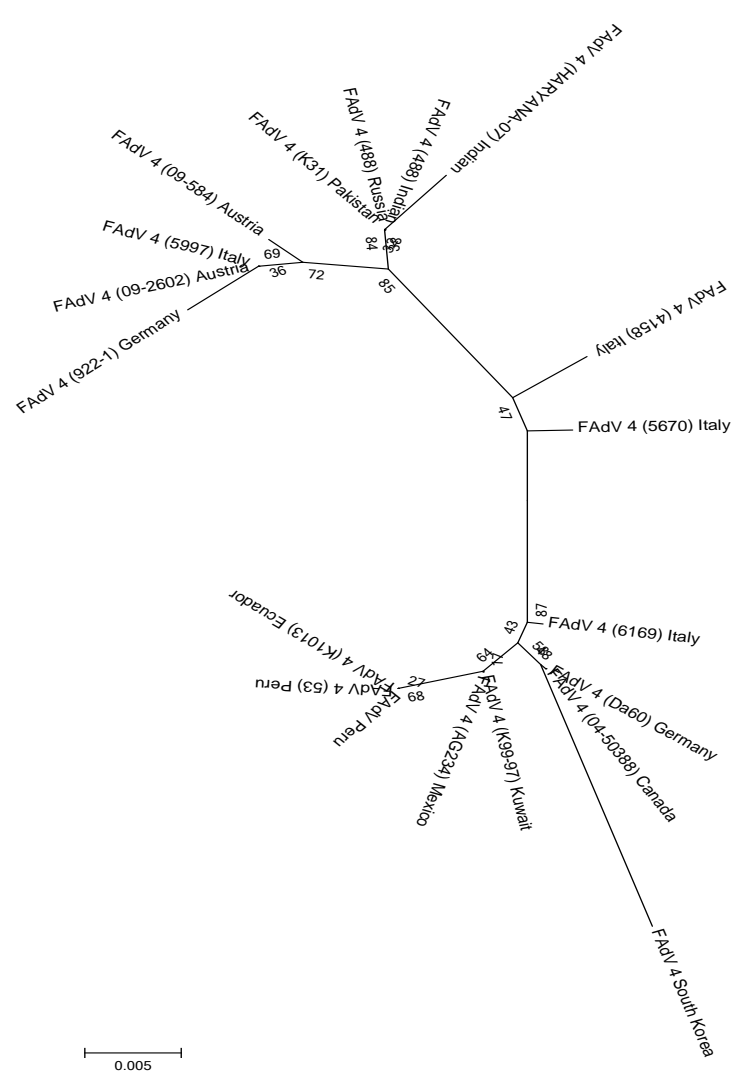

(b)

Figure 2. (a) Phylogenetic tree of L1 loop of the hexon nucleotide sequence from FAdV C serotype 4. The evolutionary relationships of taxa were inferred using Neighbor-Joining method [17]. The evolutionary distances were computed using the Kimura 2-parameter method [13]. The analysis involved 19 nucleotide sequences and 611 nucleotide positions in the final dataset, the strain names are according to Table 2. Bootstrap [16] test (1000 replicates) is expressed in \% values. The scale bar indicates the evolutionary distance between sequences. (b) Phylogenetic tree of L1 loop of the hexon protein sequence from FAdV C serotype 4. The evolutionary relationships of taxa were inferred using Neighbor-Joining method [17]. The evolutionary distances were computed using the Dayhoff matrix method [14]. The analysis involved 19 amino acid sequences and 202 amino acid positions in the final dataset, the strain names are according to Table 2. Bootstrap [16] test (1000 replicates) is expressed in \% values. The scale bar indicates the evolutionary distance between sequences.

During this study we analyzed 47 FAdV isolates from IBH clinical cases, examined their Hexon gene loop 1 sequences and compared them with reference strains previously published sequences. Our results suggest the absence of genetic variability in FAdV C in Peru, similar to previous reports [19]; however this study only has access to one Peruvian isolate. Similar results were reported from India [22] [23] and South Korea [24] for clinical cases of IBH associated with the presence of FAdV C serotype 4 ( $>99 \%$ clinical cases of IBH). However, FAdV C serotype 4 (strain K531) is also associated with hydropericardium syndrome outbreaks (HPS) from South Korea [24] [25] and Germany [26] in contrast with Peruvian FAdV C serotype 4 than only reports IBH clinical lesions. The amino acid sequence analysis shows a slight differentiation between isolates from Peru and South Korea (Table 4) and phylogenetic analysis corroborates the different genetic clustering (Figure 2(B)).

The presence of multiple FAdV species in clinical cases of IBH were reported in Canada [6] with a fixation of FAdV serotypes 8 (45\%) and 11 (45\%) and South Korea [27] with FAdV serotype 4 (60\%) and 11 (40\%), however South Korean FAdV serotype 4 showed clinical hydropericardium/ IBH lesions in contrast to the Canadian report [6].

This study is the first report of genetic characterization of FAdV C isolates from Peru that includes samples from a coastal region (Ica, La Libertad and Lima regions) which concentrates $80 \%$ of poultry production systems in Peru and provides important information than can serve as starting point for further investigations related to pathogenicity, antigenic properties and specific vaccine development for prevention and control of IBH 
Table 4. Pairwise estimates of evolutionary divergence ${ }^{1}$ of nucleotide sequences (below diagonal) and amino acid sequence (above diagonal) between 19 strain of FAdV-C serotype 4.

\begin{tabular}{|c|c|c|c|c|c|c|c|c|c|c|c|c|c|c|c|c|c|c|c|}
\hline & 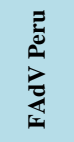 & 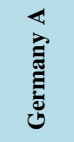 & 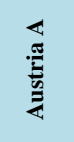 & 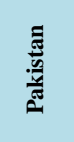 & 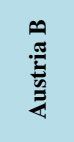 & ટ્ّ" & 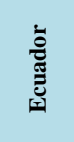 & 离 & 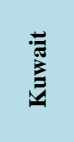 & 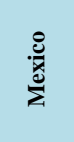 & 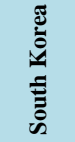 & 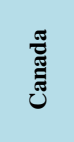 & 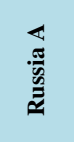 & $\frac{\pi}{\frac{\lambda}{\Xi}}$ & $\frac{\infty}{\frac{\pi}{\pi}}$ & $\begin{array}{l}u \\
\frac{\lambda}{\Xi}\end{array}$ & 贫 & $\underset{\Xi}{\mathbb{\Xi}}$ & 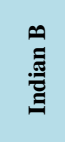 \\
\hline FAdV Peru & & 0.050 & 0.045 & 0.035 & 0.045 & 0.000 & 0.000 & 0.010 & 0.005 & 0.005 & 0.025 & 0.010 & 0.035 & 0.030 & 0.045 & 0.010 & 0.025 & 0.035 & 0.040 \\
\hline Germany A & 0.029 & & 0.005 & 0.015 & 0.010 & 0.050 & 0.050 & 0.040 & 0.045 & 0.045 & 0.045 & 0.040 & 0.015 & 0.030 & 0.005 & 0.045 & 0.030 & 0.015 & 0.020 \\
\hline Austria A & 0.023 & 0.008 & & 0.010 & 0.005 & 0.045 & 0.045 & 0.035 & 0.040 & 0.040 & 0.040 & 0.035 & 0.010 & 0.025 & 0.000 & 0.040 & 0.025 & 0.010 & 0.015 \\
\hline Pakistan & 0.023 & 0.008 & 0.007 & & 0.010 & 0.035 & 0.035 & 0.035 & 0.030 & 0.030 & 0.050 & 0.035 & 0.000 & 0.020 & 0.010 & 0.035 & 0.020 & 0.000 & 0.005 \\
\hline Austria B & 0.026 & 0.011 & 0.007 & 0.010 & & 0.045 & 0.045 & 0.040 & 0.040 & 0.040 & 0.045 & 0.040 & 0.010 & 0.020 & 0.005 & 0.035 & 0.020 & 0.010 & 0.015 \\
\hline Peru & 0.000 & 0.029 & 0.023 & 0.023 & 0.026 & & 0.000 & 0.010 & 0.005 & 0.005 & 0.025 & 0.010 & 0.035 & 0.030 & 0.045 & 0.010 & 0.025 & 0.035 & 0.040 \\
\hline Germany B & 0.007 & 0.028 & 0.020 & 0.023 & 0.023 & 0.007 & 0.008 & & 0.005 & 0.005 & 0.015 & 0.000 & 0.035 & 0.025 & 0.035 & 0.005 & 0.020 & 0.035 & 0.040 \\
\hline Kuwait & 0.005 & 0.029 & 0.021 & 0.021 & 0.025 & 0.005 & 0.007 & 0.002 & & 0.000 & 0.020 & 0.005 & 0.030 & 0.025 & 0.040 & 0.005 & 0.020 & 0.030 & 0.035 \\
\hline Mexico & 0.007 & 0.031 & 0.023 & 0.023 & 0.026 & 0.007 & 0.008 & 0.003 & 0.002 & & 0.020 & 0.005 & 0.030 & 0.025 & 0.040 & 0.005 & 0.020 & 0.030 & 0.035 \\
\hline South Korea & 0.016 & 0.028 & 0.026 & 0.026 & 0.026 & 0.016 & 0.018 & 0.010 & 0.011 & 0.013 & & 0.015 & 0.050 & 0.040 & 0.040 & 0.020 & 0.035 & 0.050 & 0.054 \\
\hline Canada & 0.008 & 0.029 & 0.021 & 0.025 & 0.025 & 0.008 & 0.010 & 0.002 & 0.003 & 0.005 & 0.011 & & 0.035 & 0.025 & 0.035 & 0.005 & 0.020 & 0.035 & 0.040 \\
\hline Russia A & 0.023 & 0.008 & 0.007 & 0.000 & 0.010 & 0.023 & 0.025 & 0.023 & 0.021 & 0.023 & 0.026 & 0.025 & & 0.020 & 0.010 & 0.035 & 0.020 & 0.000 & 0.005 \\
\hline Italy A & 0.025 & 0.020 & 0.018 & 0.015 & 0.015 & 0.025 & 0.026 & 0.021 & 0.023 & 0.025 & 0.021 & 0.023 & 0.015 & & 0.025 & 0.020 & 0.010 & 0.020 & 0.025 \\
\hline Italy B & 0.026 & 0.005 & 0.003 & 0.003 & 0.007 & 0.026 & 0.028 & 0.023 & 0.025 & 0.026 & 0.023 & 0.025 & 0.003 & 0.015 & & 0.040 & 0.025 & 0.010 & 0.015 \\
\hline Italy C & 0.011 & 0.026 & 0.021 & 0.021 & 0.025 & 0.011 & 0.013 & 0.005 & 0.007 & 0.008 & 0.011 & 0.007 & 0.021 & 0.016 & 0.021 & & 0.015 & 0.035 & 0.040 \\
\hline Indian A & 0.023 & 0.008 & 0.007 & 0.000 & 0.010 & 0.023 & 0.025 & 0.023 & 0.021 & 0.023 & 0.026 & 0.025 & 0.000 & 0.015 & 0.003 & 0.021 & 0.015 & & 0.005 \\
\hline Indian B & 0.025 & 0.010 & 0.008 & 0.002 & 0.011 & 0.025 & 0.026 & 0.025 & 0.023 & 0.025 & 0.028 & 0.026 & 0.002 & 0.016 & 0.005 & 0.023 & 0.016 & 0.002 & \\
\hline
\end{tabular}

${ }^{1}$ Analyses were conducted using p-distance [18]. This distance is the proportion (p) of amino acid (nucleotide) sites at which the two sequences to be compared are different. ${ }^{2}$ The FAdV strain accession number: Germany A (FN869978.1), Austria A (FN869977.1), Pakistan (FN869976.1), Austria B (FN869975.1), Peru (FN869973.1), Ecuador (FN869972.1), Germany B (FN869971.1), Kuwait (FN869970.1), Mexico (FN869969.1), South Korea (HQ697593.1), Canada (EF685395.1), Russia A (AY581295.1), Italy A (HM592284.1), Italy B (HM592281.1), Italy C (HM592277.1), Italy D (HM592274.1), Indian A (AY581295.1), Indian B (EU847626.1) and Fad VPeru (this study).

associated with FAdV.

\section{Conclusion}

In conclusion, our results indicate the presence of FAdV C, serotype 4, genotype C1 circulating in clinical cases of IBH from Peruvian broilers.

\section{Acknowledgements}

This work was supported by Bioservice SRL. The authors wish to thanks to Dr. Karina Mendoza, Dr. Katherine Porturas, Dr. Stephane Lovon, Dr. Brenda Jara, Dr. Madeline Garcia, Dr. Heberht Uchuya and Dr. Jhonatan Castro for their cooperation in the collection and isolation of viral samples. We would like to also thank Dr. Manuel Moro for editorial comments and suggestions.

\section{References}

[1] McFerran, J.B. and Smyth, J.A. (2000) Avian Adenoviruses. Revue Scientifique et Technique, 19, 589-601. 
[2] Hess, M. (2000) Detection and Differentiation of Avian Adenoviruses: A Review. Avian Pathology, 29, 195-206. http://dx.doi.org/10.1080/03079450050045440

[3] Nakamura, K., Mase, M., Yamaguchi, S., Shibahara, T. and Yuasa, N. (1999) Pathologic Study of Specific-PathogenFree Chicks and Hens Inoculated with Adenovirus Isolated from Hydropericardium Syndrome. Avian Diseases, 43, 414-423. http://dx.doi.org/10.2307/1592638

[4] Toro, H., Prusas, C., Raue, R., Cerda, L., Geisse, C., Gonzalez, C. and Hess, M. (1999) Characterization of Fowl Adenoviruses from Outbreaks of Inclusion Body Hepatitis/Hydropericardium Syndrome in Chile. Avian Diseases, 43, 262270. http://dx.doi.org/10.2307/1592616

[5] Chandra, R., Shukla, S.K. and Kumar, M. (2000) Thehydropericardium Syndrome and Inclusion Body Hepatitis in Domestic Fowl. Tropical Animal Health and Production, 32, 99-111. http://dx.doi.org/10.1023/A:1005230703093

[6] Ojkic, D., Martin, E., Swinton, J., Vaillancourt, J.P., Boulianne, M. and Gomis, S. (2008) Genotyping of Canadian Isolates of Fowl Adenoviruses. Avian Pathology, 37, 95-100. http://dx.doi.org/10.1080/03079450701805324

[7] Alvarado, I.R., Villegas, P., El-Attrache, J., Jensen, E., Rosales, G., Perozo, F. and Purvis, L.B. (2007) Genetic Characterization, Pathogenicity, and Protection Studies with an Avian Adenovirus Isolate Associated with Inclusion Body Hepatitis. Avian Diseases, 51, 27-32. http://dx.doi.org/10.1637/0005-2086(2007)051[0027:GCPAPS]2.0.CO;2

[8] Raue, R. and Hess, M. (1998) Hexon Based PCRs Combined with Restriction Enzyme Analysis for Rapid Detection and Differentiation of Fowl Adenoviruses and Egg Drop Syndrome Virus. Journal of Virological Methods, 73, 211217. http://dx.doi.org/10.1016/S0166-0934(98)00065-2

[9] Meulemans, G., Boschmans, M., van den Berg, T.P. and Decaesstecker, M. (2001) Polymerase Chain Reaction Combined with Restriction Enzyme Analysis for Detection and Differentiation of Fowl Adenoviruses. Avian Pathology, 30, 655-660. http://dx.doi.org/10.1080/03079450120092143

[10] Meulemans, G., Couvreur, B., Decaesstecker, M., Boschmans, M. and van den Berg, T.P. (2004) Phylogenetic Analysis of Fowl Adenoviruses. Avian Pathology, 33, 164-170. http://dx.doi.org/10.1080/03079450310001652086

[11] Thompson, J.D., Givson, T.J., Plewniak, F., Jeanmougin, F. and Higgins, D.G. (1997) The Clustal_X Windows Interface: Flexible Strategies for Multiple Sequence Alignment Aided by Quality Analysis Tools. Nucleic Acids Research, 24, 4876-4882. http://dx.doi.org/10.1093/nar/25.24.4876

[12] Tamura, K., Peterson, D., Peterson, N., Stecher, G., Nei, M. and Kumar, S. (2011) MEGA5: Molecular Evolutionary Genetics Analysis Using Maximum Likelihood, Evolutionary Distance, and Maximum Parsimony Methods. Molecular Biology and Evolution, 28, 2731-2739. http://dx.doi.org/10.1093/molbev/msr121

[13] Kimura, M. (1980) A Simple Method for Estimating Evolutionary Rate of Base Substitutions through Comparative Studies of Nucleotide Sequences. Journal of Molecular Evolution, 16, 111-120. http://dx.doi.org/10.1007/BF01731581

[14] Schwarz, R. and Dayhoff, M. (1979) Matrices for Detecting Distant Relationships. In: Dayhoff, M., Ed., Atlas of Protein Sequences, National Biomedical Research Foundation, 353-358.

[15] Saitou, N. and Nei, M. (1987) The Neighbor-Joining Method: A New Method for Reconstructing Phylogenetic Trees. Molecular Biology and Evolution, 4, 406-425.

[16] Felsenstein, J. (1985) Confidence Limits on Phylogenies: An Approach Using the Bootstrap. Evolution, 39, 783-791. http://dx.doi.org/10.2307/2408678

[17] Tamura, K., Nei, M. and Kumar, S. (2004) Prospects for Inferring Very Large Phylogenies by Using the NeighborJoining Method. Proceedings of the National Academy of Sciences of the United States of America, 101, 11030-11035. http://dx.doi.org/10.1073/pnas.0404206101

[18] Nei, M. and Kumar, S. (2000) Molecular Evolution and Phylogenetics. Oxford University Press, New York, 18.

[19] Marek, A., Günes, A., Schulz, E. and Hess, M. (2010) Classification of Fowl Adenoviruses by Use of Phylogenetic Analysis and High-Resolution Melting-Curve Analysis of the Hexon L1 Gene Region. Journal of Virological Methods, 170, 147-154. http://dx.doi.org/10.1016/j.jviromet.2010.09.019

[20] Crawford-Miksza, L. and Shnurr, D.P. (1996) Analysis of 15 Adenovirus Hexon Proteins Reveals the Location and Structure of Seven Hypervariable Regions Containing Serotype-Specific Residues. Journal of Virology, 70, 1836-1844.

[21] Ojkic, D. and Nagy, E. (2000) The Complete Nucleotide Sequence of Fowl Adenovirus Type 8. Journal of General Virology, 81, 1833-1837.

[22] Gaba, A., Parmar, H., Pal, J.K. and Prajapati, K.S. (2010) Isolation, Identification and Molecular Characterization of Inclusion Body Hepatitis Virus. Veterinary World, 3, 415-417.

[23] Parthiban, S., Manoharan, S., Roy, P., Chandranm, N., Aruni, A.W. and Koteeswaran, A. (2005) Nucleotide Sequence Analysis of the L1 Loop Variable Region of Hexon Gene of Fowl Adenovirus 4 Isolates from India. Acta Virologica, 49, 65-68. 
[24] Lim, T.H., Lee, H.J., Lee, D.H., Lee, Y.N., Park, J.K., Youn, H.N., Kim, M.S., Youn, H.S., Lee, J.B., Park, S.Y., Choi, I.S. and Song, C.S. (2011) Identification and Virulence Characterization of Fowl Adenoviruses in Korea. Avian Disease, 55, 554-560. http://dx.doi.org/10.1637/9730-032011-Reg.1

[25] Kim, J.N., Byun, S.H., Kim, M.J., Kim, J., Sung, H.W. and Mo, L.P. (2008) Outbreaks of Hydropericardium Syndrome and Molecular Characterization of Korean Fowl Adenoviral Isolates. Avian Disease, 52, 526-530. http://dx.doi.org/10.1637/8178-112207-Case

[26] Hess, M., Raue, R. and Prusas, C. (1999) Epidemiological Studies on Fowl Adenoviruses Isolated from Cases of Infectious Hydropericardium. Avian Pathology, 28, 433-439. http://dx.doi.org/10.1080/03079459994443

[27] Choi, K.S., Kye, S.J., Kim, J.Y., Jeon, W.J., Lee, E.K., Park, K.Y. and Sung, H.W. (2012) Epidemiological Investigation of Outbreaks of Fowl Adenovirus Infection in Commercial Chickens in Korea. Poultry Science, 91, 2502-2506. http://dx.doi.org/10.3382/ps.2012-02296 
Scientific Research Publishing (SCIRP) is one of the largest Open Access journal publishers. It is currently publishing more than 200 open access, online, peer-reviewed journals covering a wide range of academic disciplines. SCIRP serves the worldwide academic communities and contributes to the progress and application of science with its publication.

Other selected journals from SCIRP are listed as below. Submit your manuscript to us via either submit@scirp.org or Online Submission Portal.
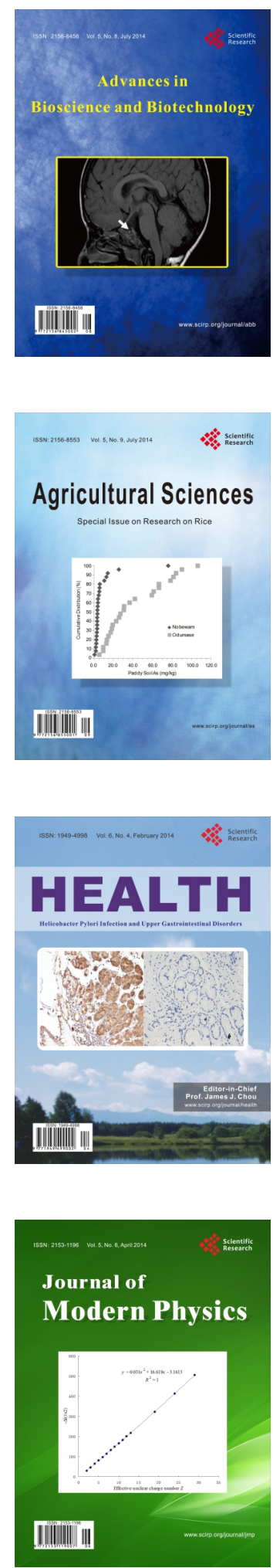
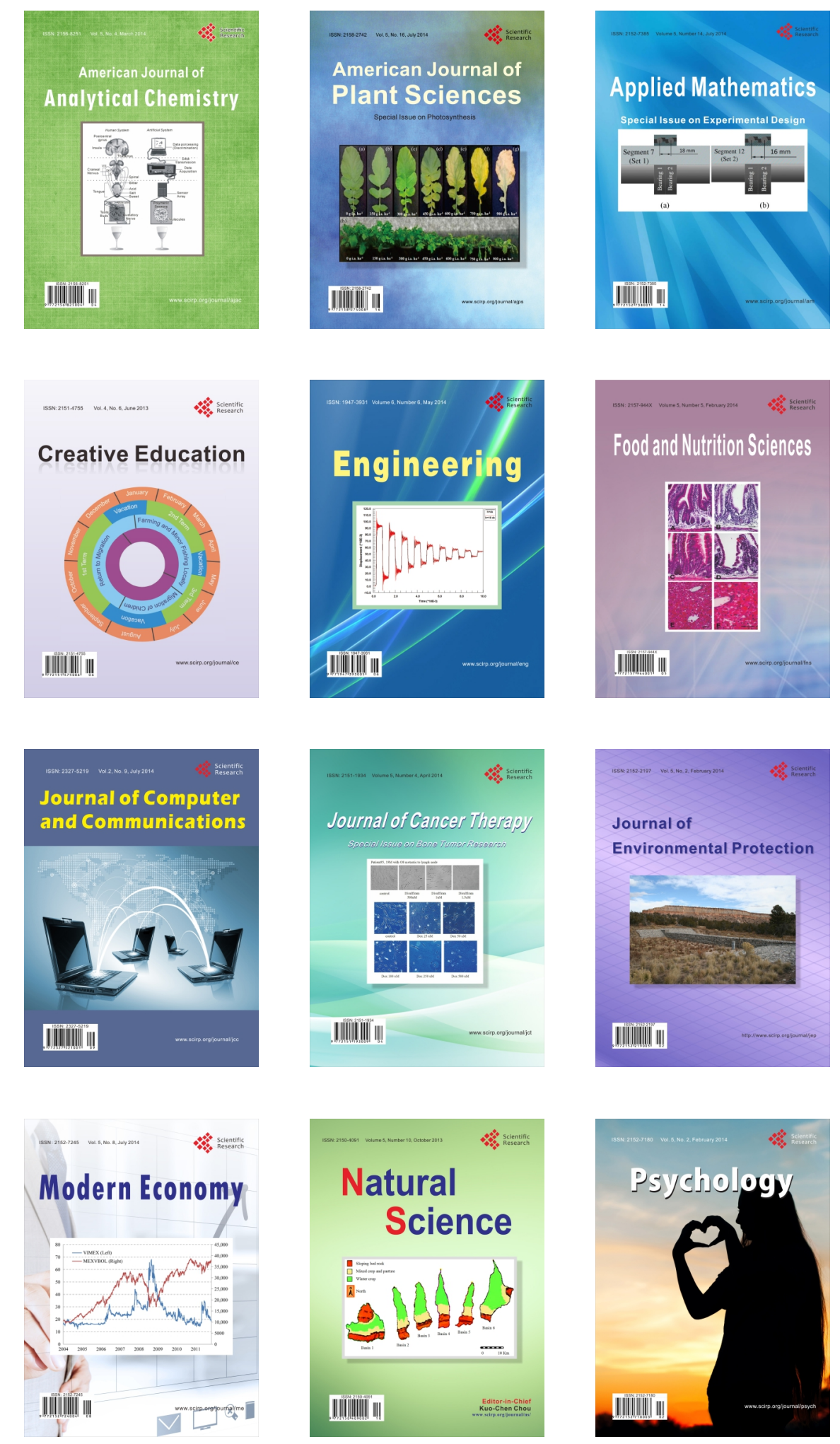